\title{
Analysis of Problems Existing in Technology Incubation in Colleges and Universities
}

\author{
Yuanfei Xue, Haigang Xu \\ Shenzhen Polytechnic, Guangdong, 518055, China
}

\begin{abstract}
Under the background of the reform of macro-market economy system, the realistic value of technology to modern enterprise competition is more and more prominent, and its innovation drives the development and progress of the whole society. Colleges and Universities are the main force of scientific and technological innovation, gathering rich intellectual resources and playing an irreplaceable role in building an innovation-oriented country. However, the success rate of technology incubation in colleges and universities is relatively low and individual problems emerge one after another, resulting in a certain degree of waste of resources, which is the focus that must be addressed at present. This paper briefly analyzes the problems existing in the technology incubation of colleges and universities and probes into the corresponding countermeasures.
\end{abstract}

Key words: colleges and universities; technology incubation; problem; countermeasures

\section{Introduction}

General secretary Xi Jinping has pointed out that scientific and technological innovation is the core. If we grasp scientific and technological innovation, we will grasp the "ox's nose" that affects China's overall development. Especially in the era of knowledge economy, colleges and universities are not only the main position of education, but also the important driving module of scientific and technological progress, which is crucial to promoting the national innovation and development strategy. University technology incubation is an important link of its actual value output, which is of great significance to the transformation of technological innovation into "productivity". However, in the practice process, there are still many problems affected by multiple factors, and relevant research has attracted much attention.

\section{Problems in Technology Incubation in Colleges and Universities}

As an important intelligence module in the development of modern society, colleges and universities are not only the important position of scientific research, but also the source of technology incubation. Colleges and universities in China have made remarkable achievements in technology incubation, and their social status has been rising. However, influenced by multiple factors, there are still some problems, as follows:

\subsection{Low quality}

Generally speaking, the main body of technological innovation in universities is teachers and students. As the most solid intellectual support, the level of their comprehensive quality directly affects the effect of the incubation project. At present, under the influence of a series of national policies, the innovation consciousness of teachers and students in universities has been enhanced obviously. Patent technology achievements emerge one after another, but there are some

Copyright (C) 2019 by author(s) and Frontier Scientific Research Publishing Inc.

This work is licensed under the Creative Commons Attribution International License (CC BY 4.0).

http://creativecommons.org/licenses/by/4.0/ 
difficulties in the actual incubation process. The original intention of technology research and development in many colleges and universities is to meet academic needs rather than solve objective practical needs. Moreover, they are divorced from the production and operation of enterprises in related industries, resulting in low output quality. To some extent, this exposed the lack of integrated construction of university production, learning and research. It simply adopts the path of separating the supply and demand of technical achievements, ignores the demand-oriented function of enterprises, and blindly sets up scientific research projects, which results in the lack of maturity of relevant research and development achievements, and the practicability needs to be verified, unable to attract the effective participation of enterprises. In the lack of enterprise capital resources to inject support, the university technology incubation of the subsequent lack of power, fell into a vicious circle. In addition, the consciousness of technology incubation in colleges and universities is relatively weak. Due to the influence of egoistic rational thinking, there are few inter-disciplinary and inter-school cooperation, and the research and development project direction and content are limited, resulting in the single and low quality of research results.

\subsection{Information imbalance}

From the research and development to the actual value output, the technology incubation in colleges and universities needs to go through many links, including patent certification, achievement sales, etc., and the flow of information is crucial. According to relevant information feedback, in recent years the number of university patent authorization projects has been increasing, but the number of patent sales contracts signed has not kept pace, which exposes the problem of "knowledge product" to "knowledge product" incubation. In addition to the low quality of the results, the transaction information is also not easy to ignore. Without the support of information exchange platform, the connection between universities and enterprises is no longer close. Relying solely on patent inventors is bound to slow the process of technology incubation. In addition, the transformation of scientific and technological achievements intermediary function demand more prominent. However, due to the late start of its development and the influence of traditional planned economy, a series of problems such as insufficient quantity and poor service are prominent. Lack of grasp of dynamic information of technology incubation in colleges and universities, lack of overall negotiation ability, and low professional level of relevant practitioners, unable to meet the increasingly hot demand for technology incubation in colleges and universities. Under the condition of market economy, the government, as the master of technology incubation in colleges and universities, bears the responsibility. However, it is difficult to promote effective cooperation due to the lack of a unified evaluation and evaluation mechanism for the transformation of technological achievements and the poor flow of information between interested parties.

\subsection{Lack of support}

University technology incubation needs to be supported in many ways. Technological innovation is an important part of the daily management of colleges and universities, and is closely related to the salary level and professional title evaluation of teachers. For this reason, universities have introduced a series of incentive mechanisms, but most of them focus on papers, monographs and other achievements, while the proportion of technology incubation indicators is low. This phenomenon of valuing theory over quality exists objectively and seriously restricts the pace of technological innovation. Therefore, some university researchers regard the publication of papers as the focus of scientific activities, while ignoring the final destination of research and development results. From the perspective of the strategy of comprehensively governing the country by law, the perfect legal system construction is the most powerful guarantee for the technology incubation in colleges and universities. As a matter of fact, China's legal system has been constantly developing and enriching, including the patent law of the People's Republic of China and the copyright law of the 
People's Republic of China. All regions have supplemented and extended the law on this basis, but compared with the law of the United States and other developed countries, China still has some deficiencies. For example, the main role is not clear, income distribution is not clear and so on. There is still a long way to go in the future, especially in the face of such complicated systematic engineering as technology incubation in universities. In addition, government policy support is an important factor to promote the technology incubation in universities. The government should give appropriate financial subsidy to stimulate the activity of the whole industrial chain.

\section{Countermeasures To Promote Technology Incubation in Colleges and Universities}

University technology incubation is a relatively complex systematic project. In the actual process of promotion, involving the participation of multi-interest subjects, the design of each link also put forward the requirements. Based on the above analysis and combined with the actual situation, the author puts forward the following countermeasures to promote the technology incubation in colleges and universities for reference.

\subsection{Expand talent support}

In the era of knowledge economy, talents are the first factor to promote social development, and also the key support for technology incubation in colleges and universities. Its effective construction is particularly necessary. General secretary Xi Jinping stressed that development is the top priority, talent is the first resource and innovation is the first driving force. As the main position of talent export, colleges and universities should give full play to their functions and organize a series of activities regularly or irregularly to strengthen the transformation consciousness of researchers. Colleges and universities should take the concept of reform and innovation as the first guide, break down the barriers of the traditional scientific research team, promote cross-school and cross-disciplinary interaction, enrich the knowledge of scientific researchers, share the latest achievements, so as to incubate more mature scientific and technological achievements. In order to promote the improvement of the scientific research ability of the talent team, colleges and universities can increase the cooperation with the scientific research institutions, and rely on their strong scientific research ability, vigorously introduce high-end research and development teams, so as to promote the improvement of the talent team of the technical incubation of colleges and universities. At the same time, colleges and universities should always bear in mind General secretary Xi Jinping's spirit of the "science and technology must be combined with social development", to shoulder the necessary social responsibilities, strengthen the technological innovation and economic market, relying on the integration of production, construction, integrating the advantageous resources, understanding enterprise needs, raise the quality of the university technology incubation. In addition, we should vigorously develop the intermediary personnel team of technology incubation in colleges and universities, deepen the cooperation between schools and enterprises, give full play to the role of the main position of education in colleges and universities, set up relevant professional curriculum system, and establish a sound professional title system. Under the guidance of enterprises' needs, more high-quality talents will be exported to lay the foundation for technology incubation services in universities and finally release higher social development efficiency. With the support of diversified high-quality talents and good interaction between universities and enterprises, it is bound to further improve the quality of technology incubation in universities.

\subsection{Expand service channels}

The imbalance of supply and demand information is an important factor that affects the technology incubation in colleges and universities. To be specific, the government can set up the public service platform of university technology incubation and establish its non-profit attribute, which can provide certain financial support. At the same time, relying on

"Internet plus", we have continuously expanded and improved the configuration of relevant service functions, including 
information release and information retrieval.In addition, relevant supervision should be carried out to ensure the authenticity and effectiveness of information, maintain the stable order of the economic market, and scientifically adjust regional cooperation to stimulate more drivers of social development. Therefore, universities and enterprises, as the direct beneficiaries of technology incubation, need to actively participate in it. For example, enterprises can make full use of modern scientific and technological means such as cloud computing and big data to further mine the information of technological achievements in colleges and universities, and transform it into productivity according to their actual needs to further release its application value. Colleges and universities can be oriented by the needs of enterprises, through the support of the public service platform, timely release the information of technology research and development results, and actively seek intended cooperative enterprises, strive to achieve accurate docking, and promote the transformation of technology to productivity. Furthermore, to develop the third party non-profit information service platform, to develop a professional, standard, detailed work process, work content, including docking of supply and demand information, intellectual property value assessment, etc., in a fair justice as the basic work principle of moderate extension service category, integrate with the world market, thus maximizing the successful landing technology incubation. In addition, in order to further expand the service channel, colleges and universities need to strengthen cooperation with enterprises and actively build technical managers among various professional teacher groups. Under the role of technical managers, the establishment of the ecological chain of scientific and technological achievements transformation service between universities and enterprises should be completed, the connection between the market and policy environment should be improved, and the scientific and technological services with technology transfer and intellectual property rights as the core should be promoted.

\subsection{Improve institutional guarantee}

The system is to point to everybody to abide by the work procedure or the action criterion jointly, the purpose is to make each work plan, according to the request achieves the anticipated goal. The old saying has the precept, does not have the rule not to be square. At present, the direct reason for the slow incubation process of technological achievements in Chinese universities is the low enthusiasm of researchers. Therefore, we should further improve the internal environment of colleges and universities, adhere to the democratic principle to improve the evaluation system, actively listen to the opinions of scientific researchers and teachers and students, and quantify the transformation of technological achievements.In combination with the actual performance of relevant personnel, differentiated rewards should be targeted to stimulate their innovation activities to the maximum extent, focusing on protecting their deserved economic benefits. At the same time, colleges and universities can also directly or indirectly in the form of "technical in" involved in the enterprise production and operation activities, innovation technology, the application of real-time tracking after fully ready to hatch update maintenance work, ability to maintain sustained profitability, in order to get stable income, thereby laying technology incubation fund support, establish a virtuous cycle system.In addition, from the perspective of comprehensively governing the country by law, the construction of relevant legal aspects of technology incubation in universities is crucial. As a complex system, it should further strengthen the relevance and coordination of relevant laws, supplement and innovate on the basis of existing laws, standardize the rights and responsibilities of stakeholders in the technological incubation of universities, promote the fairness of interest distribution, and ensure that there are laws to be followed for the series of work. Finally, the regional government should pay more attention to the technology incubation work in colleges and universities, vigorously publicize the relevant national legal system, and issue a series of implementation rules and supporting incentive policies, so as to promote its sustainable development. 


\section{Conclusions}

In a word, technology incubation in universities is of great significance. As a complex systematic project, it exposed the problems of low quality, information imbalance and insufficient support in the practice process. Therefore, the related work should be further implemented from the aspects of expanding talent support, expanding service channels and improving system guarantee, so as to accelerate the transformation into productivity and produce greater application value. Here, the author hopes that academic circles will continue to pay attention to this kind of research.

\section{References}

[1] Wang G, Gong Y.F. and Tong H. (2019). Research on the marketization path of technology transfer in colleges and universities. Industry and Technology Forum, 18(19):240-241.

[2] Guo B.M. (2019). Research on patent technology achievement transformation in Chinese universities and countermeasures. International Public Relations, (09):255-256.

[3] Luo J., Shi M. and Peng Q. (2019). Mao Shanying. Research on the transformation of scientific and technological achievements in universities and countermeasures from the perspective of cognitive difference of core stakeholders. Science and Technology Progress and Countermeasures, 36(13):112-117.

[4] Wang M. (2019). Exploration on the transformation of scientific and technological achievements and the construction of technology service platform in colleges and universities. Modern Economic Information, (13):365.

[5] Li X.T. and Xu F. (2018).Current situation and countermeasures of patent technology transformation in universities. China University Science and Technology, (12):38-41. 